\title{
Arthritis Interception in Patients with Psoriasis Treated with Guselkumab
}

\author{
Alen Zabotti · Ivan Giovannini · Dennis McGonagle · Salvatore De Vita • \\ Giuseppe Stinco $\cdot$ Enzo Errichetti
}

Received: November 1, 2021 / Published online: November 27, 2021

(c) The Author(s) 2021

Keywords: Guselkumab;

Psoriasis; Psoriatic arthritis

Psoriatic arthritis (PsA) is one of the main extracutaneous manifestations of psoriasis (PsO), with $20-30 \%$ of patients with $\mathrm{PsO}$ developing this condition over time [1-3]. Joint involvement typically follows $\mathrm{PsO}$ onset, although PsA may less commonly occur before or concomitantly with skin lesions [1-3]. Interestingly, growing evidence supports that patients with $\mathrm{PsO}$ go through three clinically silent and progressive stages before developing

\footnotetext{
A. Zabotti · I. Giovannini · S. De Vita

Rheumatology Institute, Department of Medicine, University of Udine, c/o Azienda Sanitaria

Universitaria Friuli Centrale, Udine, Italy

D. McGonagle

Leeds Institute of Rheumatic and Musculoskeletal

Medicine (LIRMM), University of Leeds, Leeds, UK

G. Stinco · E. Errichetti

Institute of Dermatology, Department of Medicine, University of Udine, c/o Azienda Sanitaria

Universitaria Friuli Centrale, Udine, Italy

E. Errichetti $(\bowtie)$

Institute of Dermatology, "Santa Maria della

Misericordia" University Hospital, Piazzale Santa

Maria della Misericordia, 15, 33100 Udine, Italy

e-mail: enzoerri@yahoo.it
}

clinically evident PsA ("pre-PsA"), in a "multistep PsO to PsA march" [1]. These preclinical stages are (I) immunological phase (typified by an aberrant immune system activation starting from skin, intestinal mucosa, or entheses), (II) subclinical phase (featuring soluble and/or imaging findings of joint inflammation with no clinical symptoms), and (III) prodromal phase (patients having arthralgia and fatigue without clinical evidence of arthritis, enthesitis, or spondylitis) [1]. Such a model of disease progression opens the way for an early intervention aiming to treat patients with PsO carrying a high risk of transition towards clinically fullblown synovio-entheseal inflammation ("PsA interception"), with consequent benefit on PsArelated morbidity [1-3]. Notably, two categories of predictors for PsA development have been identified in patients with $\mathrm{PsO}$, including medium/long-term (PsA development greater than 2 years) and short-term (PsA development within 2 years) predictors [2]. The latter include arthralgia (defined as musculoskeletal symptoms not explained by other diagnosis without clinical evidence of PsA) and imaging evidence of synovio-entheseal inflammation, with PsA development risk ratio being 2.15 (95\% CI 1.16-3.99) and 3.72 (95\% CI 2.12$6.51)$, respectively $[2,3]$.

Herein, we report our experience of four patients with $\mathrm{PsO}$ carrying a short-term risk of PsA development treated with guselkumab for 
Table 1 Demographic and musculoskeletal features of the guselkumab-treated patients

\begin{tabular}{|c|c|c|c|c|}
\hline & Patient 1 & Patient 2 & Patient 3 & Patient 4 \\
\hline \multicolumn{5}{|l|}{ Demographic and $\mathrm{PsO}$ data } \\
\hline $\operatorname{Sex}(M / F)$ & $\mathrm{M}$ & $\mathrm{M}$ & $\mathrm{F}$ & $\mathrm{F}$ \\
\hline Age (years) & 54 & 56 & 38 & 65 \\
\hline BMI & 24.1 & 26.3 & 23.4 & 24.2 \\
\hline Smoke (yes/no) & No & Yes & Yes & No \\
\hline Familiarity for PsA (yes/no) & Yes & No & No & No \\
\hline $\mathrm{PsO}$ (yes/no) & Yes & Yes & Yes & Yes \\
\hline $\mathrm{PsO}$ duration (years) & 25 & 10 & 8 & 10 \\
\hline $\mathrm{PsO}$ previous treatment & MTX & CYS & CYS & MTX \\
\hline PASI score & 28.2 & 24.1 & 14.2 & $8^{*}$ \\
\hline NAPSI score & 52 & 0 & 17 & 0 \\
\hline \multicolumn{5}{|l|}{ Preclinical PsA MSK features } \\
\hline Arthralgia (yes/no) & Yes & Yes & Yes & Yes \\
\hline Arthralgia duration (months) & 24 & 12 & 12 & 36 \\
\hline VAS pain $(0-10)$ & 3 & 4 & 4.5 & 7 \\
\hline Fatigue (yes/no) & Yes & No & No & No \\
\hline Tender joints count $(0-68)$ & 4 & 7 & 2 & 6 \\
\hline Swollen joints count $(0-66)$ & 0 & 0 & 0 & 0 \\
\hline Leeds Enthesitis Index (0-6) & 0 & 1 & 1 & 2 \\
\hline HAQ & 0.25 & 0.125 & 0.125 & 0.5 \\
\hline US-detected inflammatory signs (yes/no) & No & Yes & Yes & Yes \\
\hline
\end{tabular}

CYS cyclosporine, $M S K$ musculoskeletal, MTX methotrexate, $P s A$ psoriatic arthritis, $P s O$ psoriasis, US ultrasonography ${ }^{*}$ Patient had the involvement of sensitive areas (face and hands)

skin disease. It included two women and two men, with a mean age of 53.3 years (38-65 years) and a mean PsO duration of 13.3 years (8-25 years). Baseline (guselkumab beginning) mean Psoriasis Area and Severity Index (PASI) score was 18.6 (SD 9.2), with figures ranging from 8 to 28.2, whereas nail involvement was present only in two cases (case 1 and 3, with NAPSI score of 52 and 17, respectively). All the patients reported arthralgia at baseline (mean duration of 21 months, range $12-36$ months), with a mean tender joint count (TJC) of 4.74 (SD 2.2), without swollen joints and a mean VAS pain of 4.6 (SD 1.7). Sonographic evidence of subclinical active enthesitis/synovitis was present in one and three patients, respectively. More details are reported in Table 1. Guselkumab was the firstline biologic in all cases after the failure (primary/secondary) of at least one conventional treatment (i.e., methotrexate or cyclosporine). During a 1-year follow-up, no patient developed clinical arthritis and fulfilled ClASsification criteria for Psoriatic ARthritis (CASPAR). All 
patients reported a significant reduction in VAS pain after 6 months of therapy, with three patients showing a complete regression of arthralgia (no tender joint and VAS pain of 0 ) and one patient (case 4) reporting a major regression of musculoskeletal pain and TJC (Fig. 1). No sonographic sign of active synovioentheseal inflammation was observed in the present cohort from month 6; PASI 75 was reached in all cases (Fig. 1).

Guselkumab is a human immunoglobulin G1 monoclonal antibody blocking the interleukin-23 (IL-23)-mediated signaling pathway [4]. It is approved for moderate to severe plaque-type $\mathrm{PsO}$ and administered subcutaneously at the dose of $100 \mathrm{mg}$ at week 0 , week 4 , and every 8 weeks thereafter [4]. Our data support the possible usefulness of this biologic therapy to revert preclinical manifestations of PsA (i.e., arthralgia/sonographic enthesitis/synovitis) carrying a high risk of short-term development of clinically full-blown synovioentheseal inflammation, thereby potentially modifying the natural course of PsA. Interestingly, in all our patients, conventional treatments failed to control such PsA preclinical stages, thus backing a higher efficacy of anti-IL23 agents for this purpose. In this regard, IL-23R blockade has been shown to completely prevent spondylitis and arthritis development in HLAB27tg rats [5]. The same study showed that IL23 would be more involved in the initiation rather than persistence of SpA as downstream effector cytokines (IL-17A/IL-22) were downregulated only after prophylactic and not therapeutic IL-23R blockade [5].

In conclusion, guselkumab might intercept PsA during a potential "window of opportunity" in individuals with moderate-severe PsO having short-term predictors of PsA development. Randomized controlled trials are needed to confirm our preliminary findings.

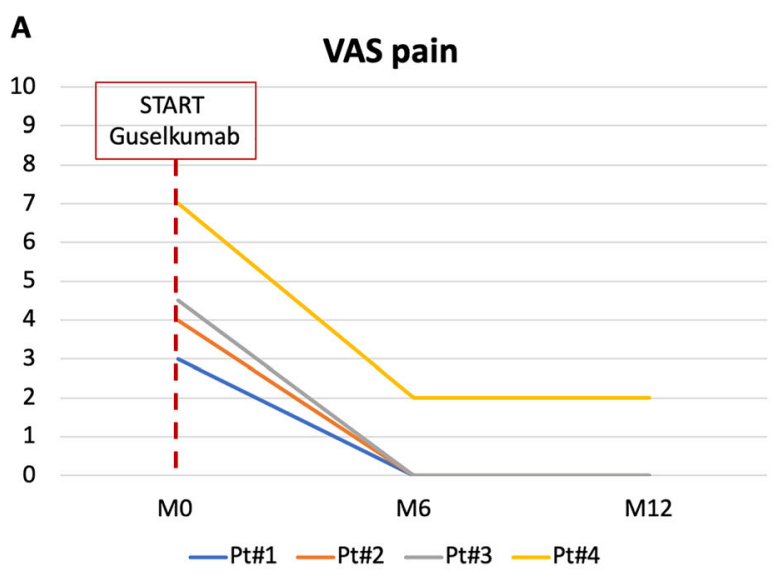

B

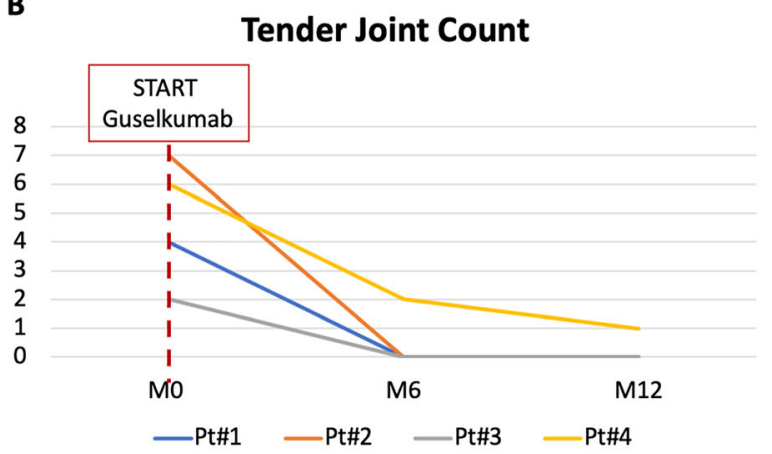

C

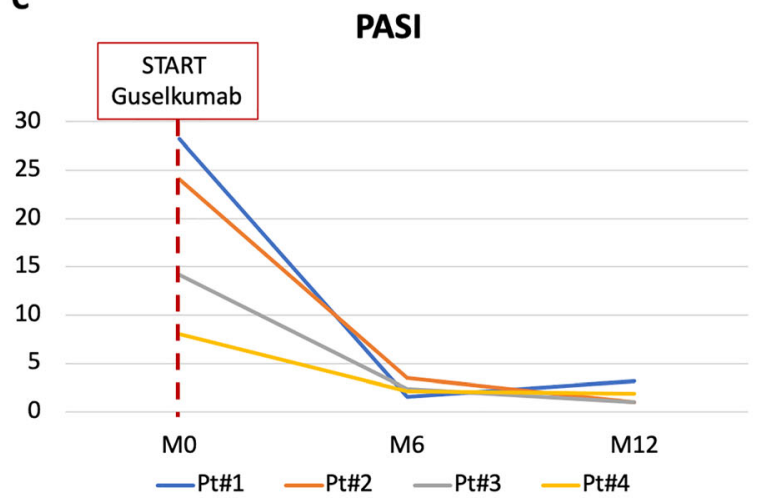

Fig. 1 Variation of VAS pain (a), tender joint count (TJC) (b), and PASI score (c) over 1 year

\section{ACKNOWLEDGEMENTS}

Funding. No funding or sponsorship was received for this study or publication of this article. 
Authorship. All named authors meet the International Committee of Medical Journal Editors (ICMJE) criteria for authorship for this article, take responsibility for the integrity of the work as a whole, and have given their approval for this version to be published.

Author Contributions. Alen Zabotti and Enzo Errichetti (concept and design + manuscript writing); Ivan Giovannini (drafting the manuscript); Dennis McGonagle, Salvatore De Vita, and Giuseppe Stinco (review of the paper).

Disclosures. Alen Zabotti has received research funding or honoraria from Novartis, Lilly, Janssen, Abbvie, Amgen, UCB. Ivan Giovannini has received research funding or honoraria from Lilly. Dennis McGonagle has received research funding or honoraria from Novartis, Lilly, Janssen, Pfizer, Abbvie, Celgene, Amgen, Gilead, UCB. Enzo Errichetti has received research funding or honoraria from Janssen and Abbvie.

Compliance with Ethics Guidelines. This article is based on previously conducted studies and does not contain any new studies with human participants or animals performed by any of the authors.

Open Access. This article is licensed under a Creative Commons Attribution-NonCommercial 4.0 International License, which permits any non-commercial use, sharing, adaptation, distribution and reproduction in any medium or format, as long as you give appropriate credit to the original author(s) and the source, provide a link to the Creative Commons licence, and indicate if changes were made. The images or other third party material in this article are included in the article's Creative Commons licence, unless indicated otherwise in a credit line to the material. If material is not included in the article's Creative Commons licence and your intended use is not permitted by statutory regulation or exceeds the permitted use, you will need to obtain permission directly from the copyright holder. To view a copy of this licence, visit http://creativecommons.org/licenses/by$\mathrm{nc} / 4.0 /$.

\section{REFERENCES}

1. Scher JU, Ogdie A, Merola JF, Ritchlin C. Preventing psoriatic arthritis: focusing on patients with psoriasis at increased risk of transition. Nat Rev Rheumatol. 2019;15:153-66.

2. Zabotti A, De Lucia O, Sakellariou G, et al. Predictors, risk factors, and incidence rates of psoriatic arthritis development in psoriasis patients: a systematic literature review and meta-analysis. Rheumatol Ther. 2021. https://doi.org/10.1007/s40744-021-00378-w.

3. Zabotti A, McGonagle DG, Giovannini I, et al. Transition phase towards psoriatic arthritis: clinical and ultrasonographic characterisation of psoriatic arthralgia. RMD Open. 2019;5:e001067.

4. Al-Salama ZT, Scott LJ. Guselkumab: a review in moderate to severe plaque psoriasis. Am J Clin Dermatol. 2018;19:907-18.

5. van Tok MN, Na S, Lao CR, et al. The initiation, but not the persistence, of experimental spondyloarthritis is dependent on interleukin-23 signaling. Front Immunol. 2018;9:1550. 